\title{
Low-Cost and High-Performance Electrospun Carbon Nanofiber Film Anodes
}

\author{
Jianxin Cai ${ }^{1}$, Wei Li ${ }^{1}$, Pengfei Zhao ${ }^{1}$, Ji Y ${ }^{2}$, Zhenyu Yang ${ }^{2, *}$ \\ ${ }^{1}$ School of Resources Environmental and Chemical Engineering, Nanchang University, No. 999 \\ Xuefu Road, Nanchang, Jiangxi,330031, P. R. China \\ ${ }^{2}$ School of Chemistry, Nanchang University, No.999 Xuefu Road, Nanchang, Jiangxi, 330031, P. R. \\ China \\ *E-mail: cjx@ncu.edu.cn
}

doi: $10.20964 / 2018.03 .43$

Received: 21 November 2017 / Accepted: 10 January 2018 / Published: 5 February 2018

\begin{abstract}
Carbon nanofiber thin membrane is a promising candidate material for chemical power supply because of its simple design and fast charge-transfer network. In this study, the original porous carbon nanofiber thin membrane electrode was electrospun following a simple and rapid washing process. The structural features of the porous carbon nanofiber membranes were characterized by scanning electron microscopy, transmission electron microscopy, X-ray diffraction, and Brunauer-Emmett-Teller analysis. The electrochemical performance of the porous carbon nanofiber membranes was investigated by electrochemical test. Results show that the as-prepared porous carbon nanofiber film possesses a highly porous surface structure and demonstrates an outstanding electrochemical performance. The film electrode exhibits a charge capacity of $948.1 \mathrm{mAh} \cdot \mathrm{g}^{-1}$ under a C-rate of $0.1 \mathrm{C}$ $\left(37.2 \mathrm{~mA} \cdot \mathrm{g}^{-1}\right)$ and $208.8 \mathrm{mAh} \cdot \mathrm{g}^{-1}$ after 1700 cycles under a C-rate of $5 \mathrm{C}\left(1860 \mathrm{~mA} \cdot \mathrm{g}^{-1}\right)$. In the preparation of a binder- and conductive-free thin film electrode, the addition of $\mathrm{NaCl}$ increases the precursor viscosity, which results in a slimmer fiber and significantly improves the specific surface area by washing $\mathrm{NaCl}$ crystals with water. This method avoids rinsing with an acidic or basic solution and recycles the used $\mathrm{NaCl}$, thereby significantly reducing the preparation cost of porous carbon fiber thin film electrode. This work demonstrates a new method of preparing high-value porous carbon fiber thin film electrodes at a low cost.
\end{abstract}

Keywords: Electrospinning, Low-Cost, Sodium chloride, Porous carbon nanofiber film, Lithium ion batteries

\section{$\underline{\text { FULL TEXT }}$}


(C) 2018 The Authors. Published by ESG (www.electrochemsci.org). This article is an open access article distributed under the terms and conditions of the Creative Commons Attribution license (http://creativecommons.org/licenses/by/4.0/). 